\title{
Periodismo inmersivo. Análisis de la narrativa en aplicaciones de realidad virtual
}

\section{Immersive journalism: a narrative analysis in virtual reality apps}

Juliana Colussi. Universidad del Rosario. Colombia.

juliana.colussi@urosario.edu.co

$[\mathrm{CV}]$ (1)

Thays Assunção Reis. Universidad Federal de Tocantins. Brasil.

thays.jornalista@gmail.com

$[\mathrm{CV}](\mathrm{C}$

Cómo citar este artículo / Referencia normalizada

Colussi, J. y Assunção Reis, T. (2020). Periodismo inmersivo. Análisis de la narrativa en aplicaciones de realidad virtual. Revista Latina de Comunicación Social, (77), 19-32. https://www.doi.org/10.4185/RLCS-2020-1447

\section{RESUMEN}

Esta investigación, que se enmarca en el campo de los estudios sobre periodismo inmersivo, compara la narrativa de los contenidos de El País VR, Folha $360^{\circ}$, Estadão RV y NYT VR, aplicaciones de realidad virtual de los diarios El País (España), Folha de S. Paulo y Estado de S. Paulo (Brasil) y New York Times (Estados Unidos). Además de identificar las principales características de 51 publicaciones, el objetivo de este estudio es verificar el nivel de inmersión que estos contenidos ofrecen al usuario. Se desarrolla un análisis de contenido basado en contribuciones metodológicas de autores de diferentes países. El resultado indica que el nivel de inmersión espacial es bastante superior al sensorial en la mayoría de la muestra, lo que conlleva a una experiencia de realidad virtual relativa para el usuario. A excepción de los contenidos de NYT VR, el usuario no se siente involucrado psicológicamente a punto de inmergir totalmente en la historia y olvidarse de la realidad. Por tanto, hace falta apostar por iniciativas más innovadoras, que contemplen narrativas con avatar digital.

PALABRAS CLAVE: periodismo inmersivo; periodismo móvil; realidad virtual; vídeos $360^{\circ}$; smartphone.

\section{ABSTRACT}

This paper, which is part of the field of immersive journalism studies, compares the narrative of contents published in El País VR, Folha $360^{\circ}$, Estadão RV and NYT VR, specific applications for 360-degree productions of the newspapers El País (Spain), Folha de S. Paulo and Estado de S. Paulo (Brazil) and New York Times (United States). In addition to identify the main characteristics of 51 publications, the main of this study is to verify the level of immersion these contents provide to the users. Due to this, a content analysis has been carried out, based on methodological contributions by authors from different countries. The final result points out that the spatial immersion level is much higher than the sensory level in most of the sample, which leads to a relative virtual reality experience for the user. Hence, with the exception of the content of NYT VR, the user does not 
usually feel involved psychologically about to immerse totally in the story and forget reality. Therefore, it is necessary to encourage the creation of more innovative initiatives with digital avatar narratives.

KEYWORDS: immersive journalism; mobile journalism; virtual reality; $360^{\circ}$ videos; smartphone.

\section{CONTENIDOS}

1. Introducción y estado de la cuestión. 1.1. Periodismo, convergencia y movilidad. 1.2. La inmersión en productos periodísticos. 2. Material y método. 3. Análisis y resultados. 3.1. Elementos de las aplicaciones. 3.2. Contenidos y recursos narrativos. 3.3. Nivel de inmersión. 4. Discusión y conclusiones. 5. Referencias.

\section{Introducción y estado de la cuestión}

La apuesta de los medios de comunicación por el desarrollo de aplicaciones propias empezó a formar parte del diseño de los modelos de negocio sobre todo a partir de 2011. Esto se debe a que el uso de apps para dispositivos móviles se ha incrementado cada año. En España, por ejemplo, en 2012 el crecimiento fue del 22\% y en 2015, del 50\% (Fundación Telefónica, 2015). Esta tendencia viene acompañada del aumento en la venta de smartphones, con una previsión de crecimiento del 2,5\% en todo el mundo (Martín, 2017).

La evolución de las especificaciones técnicas de los smartphones en conjunción con el aumento de la calidad de los datos móviles ha conllevado a la creación de nuevos tipos de aplicaciones, que combinan la realidad aumentada y la realidad virtual. Estas apps han evolucionado de manera a mejorar la calidad de las imágenes y reducir efectos molestos para los usuarios. En 2016, llegan al mercado aplicaciones que "mezclan información del mundo real con información del mundo físico [...] Recientemente, la distinción entre la realidad aumentada y la realidad virtual se ha mantenido de una forma clara" (Fundación Telefónica, 2016, p. 41). Como ejemplo de esta mezcla de realidades se encuentra la app Pokémon GO.

El planteamiento de este estudio comparativo entre las aplicaciones El País VR, Folha $360^{\circ}$, Estadão RV y NYT VR se basa en que los contenidos periodísticos en 360 grados son relativamente nuevos y se encuentran en constante evolución respecto al formato. Además, hay pocas investigaciones comparativas acerca de los contenidos periodísticos de realidad virtual producido por los diarios de referencia en diferentes países. De ahí, se justifica la relevancia de esta investigación que busca identificar las características de este tipo de producto del periodismo inmersivo (Domínguez-Martín, 2015) y el nivel de inmersión que ofrecen al usuario, enmarcando las diferencias y similitudes entre lo que se publica en las cuatro apps.

\subsection{Periodismo, convergencia y movilidad}

Con la evolución de la tecnología y las redes de conexión inalámbrica, la convergencia, la innovación y la movilidad componen la base de la producción periodística online, cada vez más marcada por la ubicuidad (Colussi, Gomes-Franco e Silva \& Rocha, 2018). Sometido a diferentes tipos de convergencia, empezando por la tecnológica, el periodismo ha pasado por adaptaciones significativas en su modus operandi (Salaverría \& García Áviles, 2008). Las empresas periodísticas, que antes del desarrollo de la web comercial se destacaban por un medio o área de referencia, pasan a actuar en diversas áreas de la comunicación. La construcción de la narrativa se ve alterada por los diferentes lenguajes que se combinan en la convergencia (Jenkins, 2006). El formato long-form 
(Longhi, 2014) es un ejemplo de este tipo de contenido, en que se exploran varios recursos multimedia -audio, vídeo, infografías interactivas, etc.- para construir un reportaje multimedia (Colussi \& Magalhães, 2016). Asimismo, las estructuras de producción de esas compañías también se ven afectadas por el proceso de convergencia. Las redacciones de los periódicos, radio, televisión e internet, que antes funcionaban separadamente, ceden espacio a las redacciones integradas (Salaverría \& Negredo, 2008), donde se plantean nuevos modelos de negocio, que incluyen por ejemplo suscripciones digitales con productos nativos para dispositivos móviles (Colussi, 2016), propios del periodismo ubicuo (Colussi, Franco-Gomes \& Rocha, 2018).

Los productos autóctonos para smartphones y tablets ganan protagonismo en los medios de referencia, sobre todo, a partir de 2011, cuando las encuestas ratifican el ascenso constante del consumo de información desde dispositivos móviles entre los más jóvenes (Reuters Institute, 2018). Antes de este periodo, los contenidos disponibles en las aplicaciones móviles de los medios de referencia en Estados Unidos, China, Brasil y varios países europeos correspondían a transposiciones de la oferta de los medios tradicionales, un modelo similar a lo que ocurrió con los primeros años del periodismo en la web (Canavilhas \& Santana, 2011). Además, se identificó, en esta época, que las apps exploraban poco las características técnicas de los dispositivos móviles.

Conviene señalar que los productos periodísticos pioneros para smartphones y tablets surgen durante la cuarta generación del periodismo en redes digitales (Barbosa, 2013). En la primera fase del periodismo móvil, el periódico brasileño Extra lanzó en 2009 el proyecto Repórter $3 G$ para la producción de contenido. Los periodistas recibían un kit para generar contenido y enviarlo a través de un smartphone (Firmino da Silva, 2015). En la fase actual los dispositivos móviles reconfiguran los procesos de producción, edición y circulación del contenido (Silveira \& Saad, 2018). También surgen, como propulsores de un escenario innovador, los productos autóctonos adaptados a las especificidades de los aparatos móviles (Colussi, 2017).

En cuanto a la innovación en el campo periodístico, se destaca la creación de laboratorios de innovación tecnológica (media labs) en los medios de referencia estadounidense y europeos. Entre los objetivos principales de este tipo de espacio en las redacciones, se encuentran: 1) desarrollar aplicaciones de contenidos informativos y 2) crear nuevos formatos y narrativas para productos periodísticos (Salaverría, 2015). A partir de estas iniciativas los medios están apostando en la creación de contenidos transmedia, como es el caso del Laboratorio de Innovación Audiovisual de Radio y Televisión Española (RTVE).

\subsection{La inmersión en productos periodísticos}

El periodismo contemporáneo busca diversas formas de acercar la audiencia a los hechos noticiosos, como pueden ser los recursos textuales o tecnológicos que favorecen experiencias de presentificación de los acontecimientos. Teniendo en cuenta también que la realidad virtual permite un mayor nivel de interactividad, los medios de comunicación están apostando por el uso de la realidad virtual (VR) para propiciar a los usuarios "una experiencia inmersiva que replica un medio ambiente real o imaginado" (Aronson-Rath, Owen, Milward \& Pitt, 2015, p. 12).

En este caso la realidad virtual se expresa a través de producciones en 360 grados generadas con el auxilio de un computador y visualizadas en players específicos para este formato o en webs que lo soportan, como YouTube o Facebook (Costa \& Brasil, 2017). Esta tecnología permite el uso de las gafas de realidad virtual, que proyectan las imágenes en pequeñas pantallas cercanas a los ojos del usuario. 
Aplicada a la elaboración de contenidos informativos, la realidad virtual surge como una nueva experticia del quehacer periodístico: el periodismo de inmersión. Consiste en la "the production of news in a form in which people can gain first-person experiences of the events or situation described in news stories" (De La Peña et al., 2010, p. 291). Domínguez-Martín (2013, p. 94) corrobora con esta perspectiva al afirmar que "el periodismo inmersivo se expresa en todo su potencial con tecnologías y equipos de realidad virtual e inmersiva, que permiten la experimentación no solo visual sino también sensorial de un entorno sintético tridimensional”.

Para el desarrollo del periodismo inmersivo, se recomienda el uso de tecnologías que logren eliminar sensorialmente la frontera física entre el individuo y el medio de comunicación (Domínguez-Martín, 2013). Esto en la práctica inmersiva supone la inmediación (immediacy), es decir, la relación ilusoria de que no hay mediación en las operaciones comunicacionales.

La idea fundamental del periodismo inmersivo es que permite al usuario tener contacto con el ambiente del acontecimiento a través de su representación en forma de avatar digital -personaje animado en 3D que se ve el mundo desde la perspectiva en primera persona. De esta manera el usuario puede moverse en el sistema inmersivo, ya que los movimientos de brazos y piernas del cuerpo virtual acompañarían el real.

The participant can also enter the story in one of several forms: as oneself, a visitor gaining

first-hand access to a virtual version of the location where the story is occurring, or through

the perspective of a character depicted in the news story. Whether visiting the space as

oneself or as a subject in the narrative, the participant is afforded unprecedented access to the

sights and sounds, and possibly, the feelings and emotions that accompany the news (De La

Peña et al., 2010, p. 292).

De La Peña (2010) aún revela que uno de los aspectos notables de la inmersión en ambientes virtuales se refiere a la tendencia de las personas respondieren de forma real a situaciones virtuales, aunque se sepa que no lo son. A este tipo de comportamiento se denomina RAIR (Response-As-IfReal), que corresponde a una "respuesta como se fuera real". Eso se da incluso cuando el nivel de fidelidad en relación con la realidad física cotidiana es bastante reducido.

En este sentido, por lo menos tres propiedades cognitivas contribuyen para crear experiencias de inmersión en periodismo desde la sensación de presencia en el ambiente representado por pantallas virtuales: 1) Lugar de ilusión -que despierta la sensación de estar u operar en un lugar remoto o virtual-; 2) Plausibilidad -la ilusión de que lo que está ocurriendo realmente acontece-; y 3) Propiedad corporal -concepción neurocientífica para designar la plasticidad del cerebro para criar representaciones corporales- (De La Peña et al., 2010).

Estas propiedades representan efectos materiales impuestos por las tecnologías mediáticas a sus mensajes (Pereira, 2015). Dichos efectos corresponden a posibles relaciones "que se estabelecem entre a materialidade dos meios e de suas mensagens com a materialidade do conjunto corpo/mente de uma dada audiência" (Pereira, 2015, p. 20).

Conviene señalar que los sistemas de realidad virtual asociados al periodismo son los únicos capaces de ofrecer experiencias en primera persona en las noticias, con un nivel de comprensión distinto de la 
RLCS, Revista Latina de Comunicación Social, 77, 19-32

[Investigación] DOI: 10.4185/RLCS-2020-1447 | ISSN 1138-5820 | Año 2020

ofrecida por la lectura de un reportaje impreso o audiovisual (De La Peña et al., 2010). De esta forma, además de informar, el periodismo inmersivo permite al usuario experimentar lo ocurrido.

En esta línea, Domínguez-Martín (2010) sostiene que la inmersión en periodismo

It can be roughly defined as story presentation that allows the Internet user to interact with

story elements or data. Instead of "reading" a story online, the user gets to "do" something -

and in the process learn, and better understand the topic. (Domínguez-Martín, 2010, p. 3)

A partir de estas reflexiones entendemos periodismo inmersivo como uno de los horizontes para el futuro de la producción periodística, ya que presenta elementos de innovación para las redacciones a la vez que ofrece caminos para ampliar las potencialidades de participación y/o interacción del individuo con elementos de las historias.

\section{Material y método}

Este estudio comparativo tiene como objetivo identificar las características de los contenidos 360 grados publicados en aplicaciones móviles y el nivel de inmersión que ofrecen al usuario, apuntando las diferencias y similitudes entre lo que se publica en cada app.

Para la realización de este trabajo, en primer lugar, se llevó a cabo una investigación de campo en junio de 2017 para seleccionar la muestra de apps de diarios de referencia en Iberoamérica específicas para la publicación de contenidos 360 grados. Para ello, se tuvo en cuenta 15 cabeceras de referencia en 9 países iberoamericanos: La Nación y Clarín (Argentina), El Mercurio y La Tercera (Chile), El Comercio (Perú), El Tiempo (Colombia), Reforma (México), Prensa Libre (Guatemala), O Estado de S. Paulo, Folha de S. Paulo y O Globo (Brasil), El País y El Mundo (España), Público y Diário de Notícias (Portugal).

En el momento en que se realizó la investigación de campo en las tiendas de Google Play y Apple Store, se identificaron que tan solo tres medios disponían de una app de contenidos en 360 grados. Las aplicaciones encontradas fueron: El País VR (España), Folha $360^{\circ}$ y Estadão RV (Brasil). Teniendo en cuenta que NYT VR fue la app precursora, decidimos incluirla en este estudio con el fin de tener más elementos de comparación entre las aplicaciones de los medios iberoamericanos.

A continuación, se llevó a cabo una observación preliminar de las apps seleccionadas para delimitar los elementos fundamentales al tener en cuenta para la realización del análisis de contenido web (Herring, 2010). Se optó por el análisis de contenido web porque contempla otras variables que el análisis de contenido tradicional (Bardin, 1977) no incluye, como pueden ser los espacios de comentarios, inserción de enlaces en los contenidos o el empleo de piezas interactivas. Para la realización del análisis de contenido, se han analizado en el caso de El País VR, Folha $360^{\circ}$ y Estadão RV, 3, 23 y 15 vídeos respectivamente, lo que corresponde a todos los contenidos disponibles en estas apps hasta el 25 de febrero de 2018. Específicamente en NYT RV, se tuvo en cuenta las últimas diez publicaciones, totalizando 51 vídeos analizados. Vale destacar que se realizó la recogida de datos con el uso de gafas de realidad virtual de tipo Cardboard. 
En este sentido, teniendo en cuenta el objetivo principal de esta investigación, se proponen las siguientes variables de análisis ${ }^{1}$ :

1. Elementos de la aplicación: identificar los menús, opciones de idioma, tipo de acceso al contenido (gratuito o por suscripción) y consumo del contenido (a través de descarga o directamente).

2. Frecuencia de publicación: contabilizar el número de contenidos disponibles en cada app para obtener un promedio de la frecuencia de publicación de los medios analizados.

3. Tema: averiguar los asuntos abordados en este tipo de contenido.

4. Duración: registrar el tiempo de duración de cada publicación.

5. Recursos narrativos: identificar el uso de los elementos que componen la narrativa 360 grados -narración en audio, fotografias, canciones, información textual, iconos, etc.-

6. Edición: verificar la calidad de las imágenes y demás elementos incluidos en los contenidos panorámicos.

7. Nivel de inmersión: averiguar los tipos y niveles de inmersión de cada historia. A partir de la propuesta de categorización de inmersión periodística de Costa y Brasil (2017), hemos tenido en cuenta las siguientes variables y categorías: a) inmersión espacial, que incluye los niveles de presencia, simulación y razonabilidad; y b) inmersión sensorial, referente a la inmersión de compromiso, adaptación y absorción (cuadro 1).

\begin{tabular}{c|c|c}
\hline Tipo de inmersión & Espacial & Sensorial \\
\hline \multirow{3}{*}{ Nivel de inmersión } & Presencia & Compromiso \\
\cline { 2 - 3 } & Simulación & Adaptación \\
\cline { 2 - 3 } & Razonabilidad & Absorción \\
\hline
\end{tabular}

Cuadro 1: tipos y niveles de inmersión en contenidos periodísticos.

Fuente: Costa y Brasil (2017).

Para determinar el nivel de inmersión, se realizó un análisis de los contenidos de realidad virtual publicados en las cuatro aplicaciones seleccionadas con base en la matriz de características visuales e interactivas de la inmersión digital desarrollada por Domínguez-Martín (2015), con el fin de clasificar los tipos y niveles de inmersión (Costa \& Brasil, 2017).

En este sentido, la investigación se desarrolló con base en las siguientes hipótesis:

H1: Considerando que la mayoría de los diarios de referencia no cuenta con un equipo específico para producciones periodísticas en 360 grados la frecuencia de publicación es baja.

H2: El desarrollo de narrativas de inmersión aún es incipiente en los medios de comunicación, lo que conlleva a la publicación de contenidos que promueven sobre todo la inmersión de tipo espacial.

\section{Análisis y resultados}

\subsection{Elementos de las aplicaciones}

La aplicación NYT VR salió a la luz en noviembre de 2015, de manera que New York Times fue el precursor en publicar contenidos periodísticos en 360 grados a través de una app nativa y con este fin específico. Por ser la aplicación pionera y priorizar la calidad técnica de sus publicaciones, NYT VR

\footnotetext{
${ }^{1}$ Las estudiantes Angie Rangel y Leidy Herrera participaron en la recogida de datos de esta investigación, como parte de actividades desarrolladas por el semillero de investigación "Estudios sobre periodismo móvil en Colombia", de la Universidad del Rosario.
} 
ha servido de referencia para otros medios de comunicación que apostaron en contenidos periodísticos de realidad virtual. Los diarios brasileños Estado de S.Paulo y Folha de S.Paulo, por su parte, lanzaron sus apps Estadão RV y Folha $360^{\circ}$ en el primer trimestre de 2017, mientras el periódico español empezó con El País VR en mayo de 2016. Vale señalar que el acceso al contenido de las cuatro aplicaciones es gratuito y que las publicaciones también están disponibles en el canal de YouTube de cada medio de comunicación. De acuerdo con la figura 1, se observa que las cuatro aplicaciones estudiadas presentan propuestas de diseño diferenciadas, siendo NYT VR y El País VR las que exploran más la imagen en detrimento de la información textual.
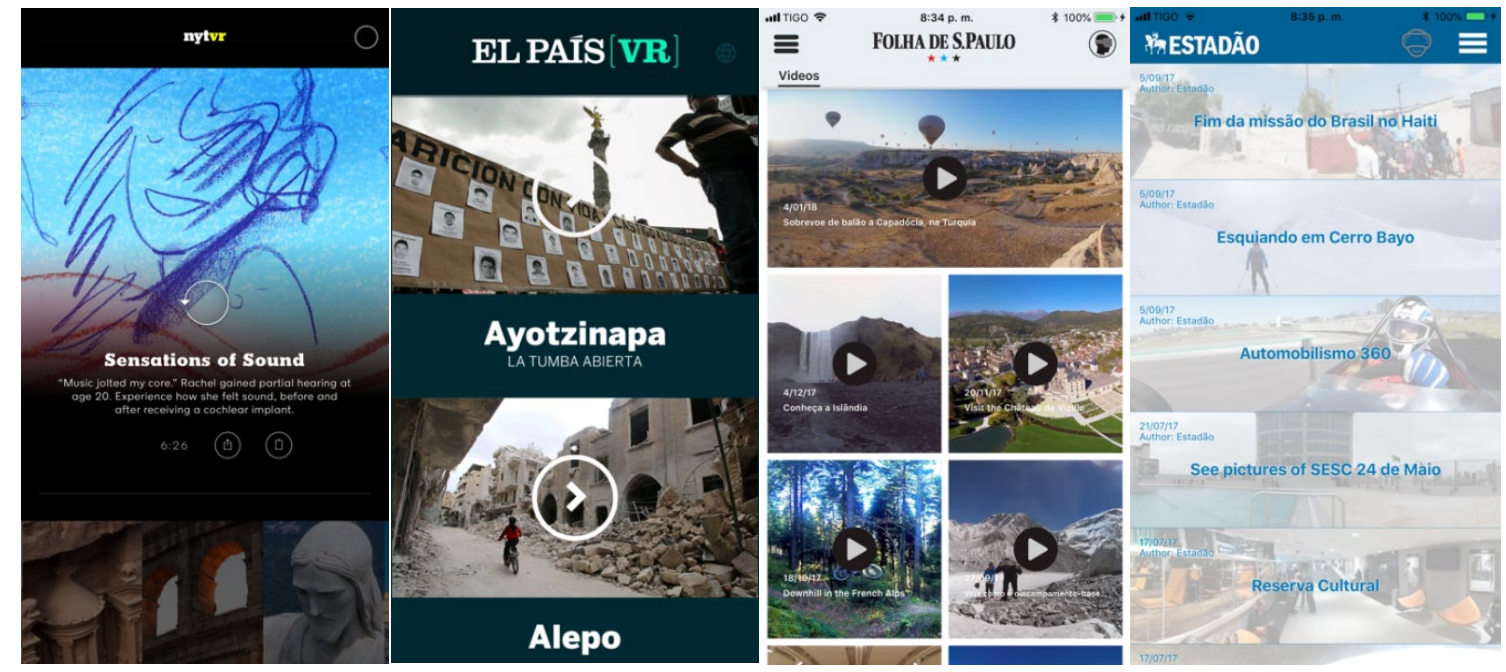

Figura 1: pantalla principal de las cuatro apps analizadas.

Fuente: captura de pantalla.

A pesar de El País haber lanzado su aplicación 360 pocos meses del surgimiento de NYT VR, su app es la más pobre entre las analizadas en este estudio. Cuenta con un menú que permite al usuario elegir entre tres idiomas -español, inglés o portugués- además de tener acceso a los tres reportajes publicados. En cuanto a los menús disponibles en la app del diario estadounidense, se destaca la presencia de un único botón en la parte superior derecha de la pantalla, que corresponde a la configuración. Al clicar en esta opción, se abre una pestaña donde el usuario encuentra tres tipos de menú: 1) Opción para activar las notificaciones para recibir una alerta cuando se publiquen nuevos videos; 2) Soporte, que ofrece dos espacios: uno que permite el usuario enviar un correo a nytvr@nytimes.com para reportar fallos y el otro que incluye las preguntas frecuentes; y 3) Sobre, donde el usuario encuentra la información sobre la versión actual de la aplicación y el número de contenidos publicados. Además de esto, la aplicación permite la compartición de contenidos vía redes sociales y WhatsApp. No obstante, para acceder al contenido compartido el usuario debe descargar la app.

Estadão RV ofrece al usuario un menú similar al de la aplicación estadounidense y Folha $360^{\circ}$ tiene un menú más sencillo, desde donde se puede acceder a los videos, compartirlos en redes sociales o descargarlos, además de obtener información técnica referente a la app.

\subsection{Contenidos y recursos narrativos}

En cuanto a la duración de los 51 videos analizados, se observa la predominancia de la producción audiovisual con menos de dos minutos, tipo microdocumental, una práctica adoptada por los cibermedios en los últimos años a raíz de la influencia de las publicaciones en redes sociales, como Facebook e Instagram. Folha $360^{\circ}$ tiene videos que varían entre 38' y 5'52', siendo "Interior da 
barraca de refugiados no Quênia" el más corto de todos los contenidos analizados, registrando un promedio de 2'49". Estadão RV sigue una dinámica similar, con la mayoría de los videos con duración de hasta cinco minutos, a excepción del video sobre los equipos culturales de la Avenida Paulista con 6'41' y un promedio de 3'06. NYT VR presenta videos entre 56' y 12'15', , siendo "The National: Something Out of Nothing" el más extenso, alcanzando un promedio de 2'52". A diferencia de las demás apps, El País VR nos llama la atención por tener videos con duración entre 4'11" y 9'20", con un promedio de 6'22", que se debe quizás al tipo de producto periodístico que, en este caso, se asemeja a grandes reportajes o documentales cortos sobre temas internacionales.

Respecto a la frecuencia de publicación, las aplicaciones de los diarios brasileños publicaron poco más de un vídeo por mes, teniendo en cuenta que Estadão RV subió su contenido más reciente en septiembre de 2017. Las tres únicas publicaciones disponibles en El País VR son de abril, julio y septiembre de 2016. Por último, NYT VR mantuvo un promedio de 2,5 videos por mes. De esta manera, los resultados de este estudio apuntan que las aplicaciones estadounidense y española presentan, respectivamente, la mayor y la menor frecuencia de publicación, siendo que esta última también es la que menos ha publicado contenidos.

Temas sobre turismo, deportes y cultura han predominado en los videos 360 grados publicados en las apps estudiadas (tabla 1). Tanto NYT VR como Folha $360^{\circ}$ exploraron lugares turísticos en un $70 \%$ y un 39\% de los videos publicados, respectivamente. Estadão RV se destaca por priorizar contenidos deportivos y culturales, mientras El País VR se dedicó exclusivamente a asuntos internacionales. Temas más complejos que se refieren a problemas internacionales o sociales tienen menos visibilidad en este tipo de contenido. En este caso, los resultados del análisis revelan que sobresalen las soft news.

Tabla 1. Temas de las publicaciones en cada aplicación.

\begin{tabular}{l|c|c|c|c}
\hline \multicolumn{1}{c|}{ Temas } & Estadão RV & Folha 360 $^{\circ}$ & El País VR & NYT VR \\
\hline Deporte & 7 & 8 & - & - \\
Cultura & 7 & - & - & 1 \\
Internacional & 1 & 4 & 3 & 1 \\
Problemas sociales & - & 2 & - & - \\
Turismo & - & 9 & - & 7 \\
Salud & - & - & - & 1 \\
Total & 15 & 23 & 3 & 10 \\
\hline
\end{tabular}

Fuente: elaboración propia.

En cuanto a los elementos narrativos utilizados en los videos 360 grados publicados en las cuatro aplicaciones, se observa que, por una parte, NYT VR se destaca por explorar imágenes en 3D e ilustraciones y cómics animados en sus videos, lo que conlleva a una experiencia de inmersión diferenciada. Nos llama la atención que El País VR combina el uso de los mismos recursos en sus tres publicaciones -audio, texto, música, imagen y sonido ambiente-. Eso demuestra que el diario español no ha explorado la combinación de diferentes recursos en este tipo de contenido (tabla 2).

Tabla 2. Recursos narrativos empleados en los vídeos $360^{\circ}$.

\begin{tabular}{l|c|c|c|c|c|c|c|c}
\hline $\begin{array}{l}\text { Apps/ Recursos } \\
\text { narrativos }\end{array}$ & $\begin{array}{c}\text { Audio } \\
\text { (off) }\end{array}$ & Texto & Música & Imagen & $\begin{array}{l}\text { Imagen } \\
\text { 3D }\end{array}$ & Ilustración & $\begin{array}{l}\text { Cómic } \\
\text { anim. }\end{array}$ & $\begin{array}{l}\text { Sonido } \\
\text { ambiente }\end{array}$ \\
\hline Estadão RV & $40 \%$ & $47 \%$ & $80 \%$ & $47 \%$ & - & - & - & - \\
Folha $360^{\circ}$ & $26 \%$ & $57 \%$ & $39 \%$ & $96 \%$ & - & $17 \%$ & - & $43 \%$ \\
El País VR & $100 \%$ & $100 \%$ & $100 \%$ & $100 \%$ & - & - & - & $100 \%$ \\
NYT VR & $30 \%$ & $80 \%$ & $90 \%$ & $20 \%$ & $70 \%$ & $60 \%$ & $10 \%$ & $80 \%$ \\
\hline
\end{tabular}

Fuente: elaboración propia. 
Folha $360^{\circ}$ y Estadão RV, por otra parte, experimentaron los recursos narrativos de forma muy regular. En el primer caso, la narrativa se restringe al uso de audio, imágenes en movimiento, música y texto. Se observa la asociación de imagen y texto o imagen y música en la mayoría de los videos analizados. En algunos contenidos, como en "Festa na av. Paulista durante a parada LGBT" o "Sobrevoo de balão a Capadócia" hay tan solo el empleo de imágenes y sonido ambiente, sin ningún tipo de información para guiar el usuario en la narrativa. En el segundo caso, prevalece la combinación de imágenes y músicas, de forma que la narración en audio, la información textual y la presencia de sonido ambiente aparecen en la minoría de los contenidos. En este sentido, la asociación de pocos recursos narrativos favorece una experiencia de inmersión menos compleja.

\subsection{Nivel de inmersión}

Respecto a los tipos y niveles de inmersión en las narrativas, se percibe una mejor ejecución de la inmersión espacial en los contenidos 360 de las cuatro aplicaciones analizadas en detrimento de la inmersión sensorial -desarrollada tan solo por NYT VR-. A excepción de Estadão RV, las demás apps cumplen con los tres niveles de inmersión espacial (tabla 3). En este caso, los videos transportan visualmente el usuario a otro contexto espacial a través de los niveles de presencia, simulación y razonabilidad, que posibilita al usuario tener la sensación de estar en un ambiente externo (Costa \& Brasil, 2017). Esta experiencia es posible gracias al uso de las gafas de realidad virtual que propicia al usuario una sensación realística de movimiento por el espacio. Además, el uso de escenarios gráficos del mundo físico asociado a los movimientos en continuidad y al dinamismo de las escenas favorece la sensación de presencia en el ambiente, inclusive en los videos sin una diversidad de recursos narrativos. Este es el caso, por ejemplo, de "Visite um castelo francês em $360^{\prime}$ " publicado en Folha $360^{\circ}$ que, al contar con imágenes, música y sonido ambiente, permite una visualización completa del jardín externo y del interior del castillo de Chateau de Vizille en Francia.

Tabla 3. Tipos y nivel de inmersión identificados en los videos de las apps.

\begin{tabular}{l|l|c|c|c|c}
\hline Tipo de inmersión & Nivel de inmersión & Estadão RV & Folha $360^{\circ}$ & El País VR & NYT VR \\
\hline \multirow{3}{*}{ Espacial } & Presencia & $\mathrm{x}$ & $\mathrm{x}$ & $\mathrm{x}$ & $\mathrm{x}$ \\
& Simulación & - & $\mathrm{x}$ & $\mathrm{x}$ & $\mathrm{x}$ \\
& Razonabilidad & $\mathrm{x}$ & $\mathrm{x}$ & $\mathrm{x}$ & $\mathrm{x}$ \\
\hline \multirow{3}{*}{ Sensorial } & Compromiso & - & - & - & $\mathrm{x}$ \\
& Adaptación & - & - & - & $\mathrm{x}$ \\
& Absorción & - & - & - & - \\
\hline
\end{tabular}

Fuente: elaboración propia.

La simulación, por su parte, posibilita que se remueva la frontera psicológica entre el observador y el espacio visual, ya que el usuario identifica y vivencia el ambiente en que está situado (Costa \& Brasil, 2017). En los videos analizados se nota que este nivel se da, sobre todo, en los contenidos en que hay focalización y ocularización interna, técnicas que favorecen la narración y la mirada del personaje. En "New seven wonders in 360: The Colosseum", de NYT VR, el video empieza con un paseo en moto por las calles de Roma dando la sensación al usuario como si fuera el acompañante del conductor. 
RLCS, Revista Latina de Comunicación Social, 77, 19-32

[Investigación] DOI: 10.4185/RLCS-2020-1447 | ISSN 1138-5820 | Año 2020
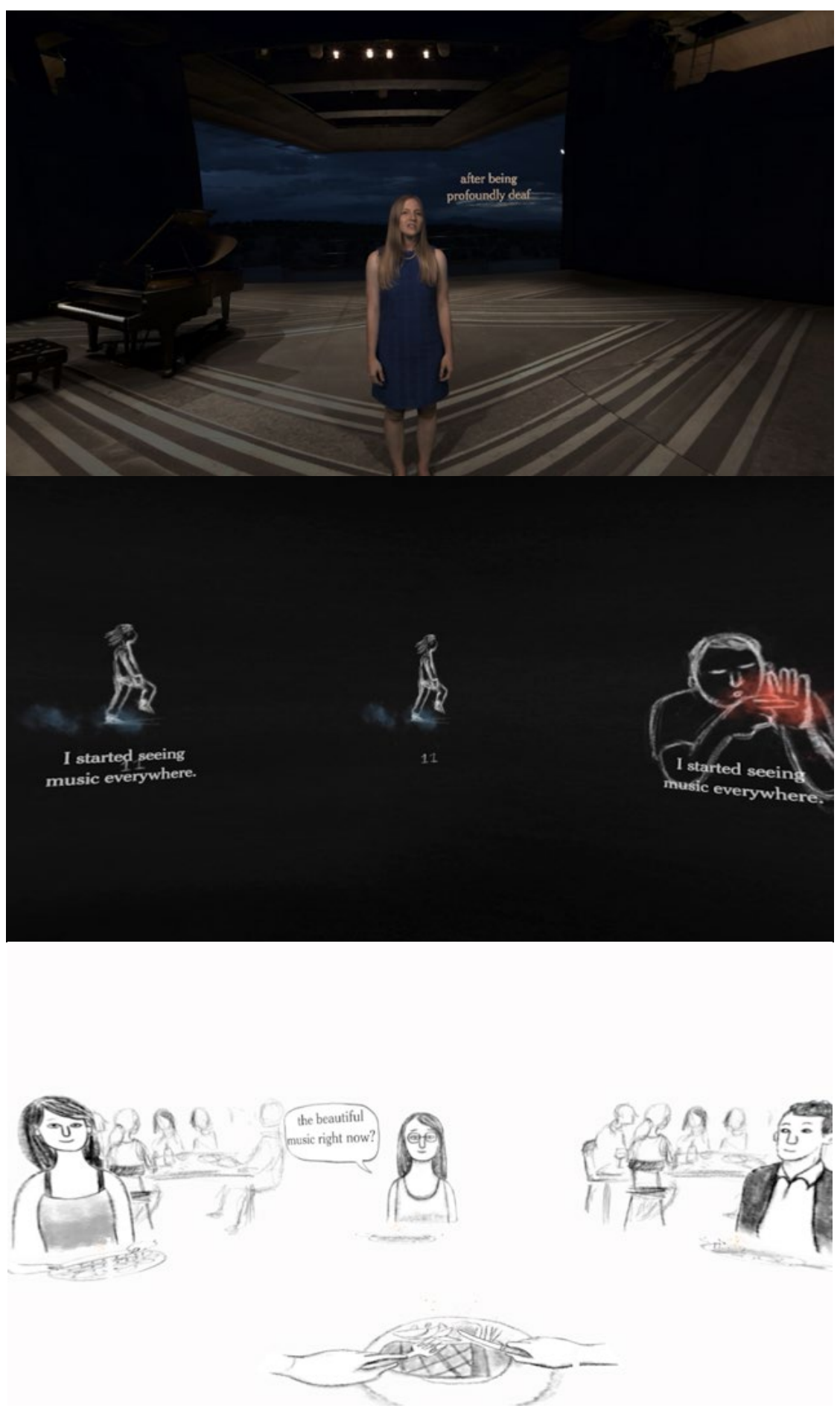

Figura 2: secuencia de la narrativa de Sensations of sound de NYT VR.

Fuente: captura de pantalla de NYT VR.

Conviene señalar que la presencia del plano de fondo del alter ego (ocularización interna secundaria) en las publicaciones 360 grados aumentan el nivel de simulación espacial, porque la identidad del personaje permanece oculta durante la narrativa, trasladando al usuario la sensación de que es el autor de las acciones presentadas en aquel espacio.

Ante la razonabilidad el usuario tiene la sensación de estar en un espacio plausible, que tenga sentido y corresponda lo máximo posible al mundo real (Costa \& Brasil, 2017). Como ejemplo se encuentra 
el reportaje "Alepo: patrulla con los cascos blancos sirios", de El País VR, en que el usuario tiene la sensación de estar presenciando las escenas hostiles propias del contexto a partir del sonido ambiente e imágenes.

En cuanto a la inmersión sensorial, NYT VR es la única aplicación que ofrece contenido en los niveles de compromiso y adaptación. El compromiso existe cuando el contenido posee elementos que posibilitan que el usuario se desconecte del mundo externo para explorar la historia, mientras la adaptación se refiere al proceso de familiarización del usuario al ambiente simulado (Costa \& Brasil, 2017). "Sensations of sound", producido por el diario estadounidense, abarca estos dos niveles de la inmersión sensorial. Al combinar imágenes grabadas en estudio con cómic animado, música, ilustración, audio y testimonio, el producto periodístico permite al usuario bucear en la historia de una chica que empezó a escuchar después de adulta (figura 2), de manera que se desconecta del exterior. Este ejemplo es el que más se acerca a una experiencia de realidad virtual en periodismo.

Ninguna de las cuatro aplicaciones ha presentado el tercer nivel de inmersión sensorial, ya que no se ha identificado la absorción total de la narrativa. En este nivel, "la obra capta la atención del usuario de tal manera que este pierde las referencias del mundo externo; y el sensu crítico sobre la calidad y el valor de verdad de lo que se presenta desaparece" (Costa \& Brasil, 2017, p. 157). En este sentido, los resultados del estudio apuntan a que no hay inmersión sensorial de tercer nivel debido a que no se ha observado una absorción total en los contenidos analizados -se ha averiguado que en algunos momentos el usuario se distrae durante el consumo del video-. La ausencia de un avatar digital para representar el usuario y potenciar la sensación de una experiencia sin mediación, así como la falta de menús para escenas y opciones en la historia, colabora para que la absorción del contenido de las narrativas en 360 grados no fuera completa.

\section{Discusión y conclusiones}

Tras la realización del análisis de 51 vídeos publicados en Estadão RV, Folha $360^{\circ}$, El País VR y NYT VR, se percata que el nivel de inmersión espacial es superior al sensorial en la mayoría del contenido analizado $(80,4 \%)$. Al ver los videos con las gafas de realidad virtual hay la sensación de presencia en el espacio, pero la relación en primera persona con las narrativas es limitada. En la mayoría de los casos el usuario no se siente involucrado psicológica o emocionalmente a punto de inmergir totalmente en la historia y olvidarse de la realidad. Tan solo la aplicación de New York Times ha empleado recursos narrativos para construir contenidos que despierten una experiencia de realidad virtual en la que se incluyen niveles de inmersión sensorial. En este sentido la investigación corrobora la hipótesis 2, que presuponía que el desarrollo de narrativas de inmersión aún es incipiente en los medios de comunicación, lo que conlleva a la publicación de contenidos que promueven sobre todo la inmersión de tipo espacial, de forma que el usuario no experimenta una inmersión sensorial a nivel de absorción (Costa \& Brasil, 2017). En otras palabras, el público no se siente involucrado psicológicamente a punto de inmergir totalmente en la historia.

El análisis llevado a cabo aún revela que los contenidos de realidad virtual no se encuentran entre las prioridades de las rutinas productivas de estos diarios de referencia. En este sentido, se ha identificado una frecuencia irregular de publicación, de forma que las aplicaciones pueden pasar meses sin publicarse ningún video. NYT VR, que es la que tiene mayor frecuencia de publicación, ha alcanzado un promedio de 2,5 videos por mes. Siendo así, se confirma la hipótesis 1 que preveía una frecuencia de publicación baja en los contenidos en 360 grados disponibles en las apps analizadas.

Aunque los resultados de este estudio confirmen el interés de los medios en invertir en un modelo de negocio en que se contempla el periodismo inmersivo a través del desarrollo de contenidos para una 
app 360 grados, hace falta apostar por iniciativas más innovadoras, de manera a experimentar narrativas con avatar digital en la que el usuario también participe en la construcción de la historia. La idea, en este caso, es que el usuario pase de observador a participante, tal como proponen De La Peña et al. (2010) y Domínguez-Martín (2015).

La innovación debería contemplar aun la producción de contenidos exclusivos para las aplicaciones, ya que los videos analizados también están disponibles en los canales de YouTube o en la web de los diarios. De esta manera, el periodismo inmersivo posibilitaría al usuario experiencias de realidad virtual más innovadoras, como puede ser la combinación de niveles de inmersión espacial y sensorial con elementos de realidad aumentada. Como parte de la innovación, se podría trabajar temas relacionados con las hard news, que aparecen en la muestra de esta investigación con una frecuencia muy baja, de manera que se predominan las soft news.

Este estudio, a pesar de su limitación, lanza luz sobre cómo se están produciendo los contenidos periodísticos de realidad virtual. Sin embargo, para responder cuestiones específicas sobre las estrategias de producción de este tipo de contenido y del modelo de negocio adoptado por cada medio de comunicación, en futuros trabajos hace falta realizar una investigación de campo con entrevista a profesionales. De igual modo es necesario conocer detalles respecto al consumo de este tipo de contenido.

\section{Referencias}

Aronson-Rath, R., Owen, T., Milward, J. \& Pitt, F. (2015). Virtual Reality Journalism. Tow Center for Digital Journalism, Columbia Journalism School.

Barbosa, S. (2013). Jornalismo convergente e continuum multimídia na quinta geração do jornalismo nas redes digitais. In J. Canavilhas (Ed.), Notícias e mobilidade (pp. 33-54). Labcom.

Bardin, L. (1977). Análise de conteúdo. Edições, 70.

Canavilhas, J. \& Santana, D. C. (2011). Jornalismo para plataformas móveis de 2008 a 2011: da autonomia à emancipação. Líbero, 14(28), 53-66.

Colussi, J. \& Magalhães, L. F. (2016). Do game a galerias dinâmicas na narrativa jornalística hipermídia: análise do especial 'A batalha de Belo Monte' da Folha de S.Paulo. Brazilian Journalism Research,12(1), 176-193. https://doi.org/10.25200/BJR.v12n1.2016.786

Colussi, J. (2016). Cartografia dos Aplicativos de Jornais Ibero-Americanos para iPad. Ancora Revista Latino-americana de Jornalismo, (3), 27-41. https://doi.org/10.21204/2359$\underline{375 X / a n c o r a . v 3 n 1 p 27-41}$

Colussi, J. (2017). Características da produção audiovisual no ZH Noite. Sessões do Imaginário, (22), 70-76. http://dx.doi.org/10.15448/1980-3710.2017.1.24169

Colussi, J., Franco-Gomes e Silva, F. y Rocha, P. M. (Eds.) (2018). Periodismo ubicuo: convergencia e innovación en las nuevas redacciones. Editorial Universidad del Rosario.

Costa, L. \& Brasil, A. (2017). Realidade virtual: inovação técnica e narrativa no jornalismo imersivo. Revista Contemporânea/Comunicação e Cultura, 15(1), 141-161. http://dx.doi.org/10.9771/1809$\underline{9386 \text { contemporanea.v15i1.21417 }}$ 
De La Peña, N., Weil, P., Llobera, J., Giannopoulos, E., Pomés, A., Spanlang, B., Friedman, D., Sanches-Vives, M. \& Slater, M. (2010). Immersive Journalism: Immersive Virtual Reality for the First-Person Experience of News. Presence, 19(4), 291-301.

Domínguez-Martín, E. (2015). Periodismo inmersivo o cómo la realidad virtual y el videojuego influyen en la interfaz e interactividad del relato de actualidad. El profesional de la información, 24(4), 413-423. https://doi.org/10.3145/epi.2015.jul.08

Domínguez-Martín, E. (2013). Periodismo inmersivo. Fundamentos para una forma periodística basada en la interfaz y en la acción. Tesis de doctorado. Barcelona: Universitat Ramon Llull (Comunicación).

Domínguez-Martín, E. (2010). Los nuevos formatos inmersivos y su aplicación en el periodismo. In II Congreso Internacional de Ciberperiodismo y Web 2.0. Universidad del País Vasco. Bilbao, 10-12 noviembre.

Firmino da Silva, F. (2015). Jornalismo móvel. Salvador. EDUFBA.

Fundación Telefónica (2015). La Sociedad de la Información en España 2015. Ariel.

Fundación Telefónica (2016). La Sociedad de la Información en España 2016. Ariel.

Herring, S. (2010). Web content analysis: Expanding the paradigm. In J. Hunsinger et al. (Eds.), International Handbook of Internet Research (pp. 233-249). Springer Verlag.

Jenkins, H. (2009). A cultura da convergência. Aleph.

Longhi, R. (2014). O turning point da grande reportagem multimedia. Revista Famecos, 21(3), 897 917.

Martín, A. M. (2017). En 2017 se venderán 1.520 millones de smartphones en todo el mundo. El Independiente. https://bit.ly/2QbHKSD

Pereira, V. A. (2015). Episódios midiáticos extremos. Dinâmicas Contemporâneas de Comunicação e Pesquisas Neuromidiáticas. Revista Contracampo, 32(2), 18-35.

https://doi.org/10.5327/Z22382577201500320764

Reuters Institute (2018). Digital News Report 2018. http://www.digitalnewsreport.org/

Salaverría, R. y García Avilés, J. A. (2008). La convergencia tecnológica en los medios de comunicación: retos para el periodismo. Trípodos, (23), 31-47.

Salaverría, R. (2015). Los labs como fórmula de innovación en los medios. El profesional de la información, 24(4), 397-404. https://doi.org/10.3145/epi.2015.jul.06

Salaverría, R. \& Negredo, S. (2008). Periodismo Integrado. Convergencia de Medios y Reorganización de Redacciones. Editorial Sol 90.

Silveira, S. C. \& Saad, E. (2018). A evolução do jornalismo ubíquo e suas características fundamentais. In J. Colussi, F. Franco-Gomes e Silva \& P. M. Rocha (Eds.), Periodismo ubicuo: 
convergencia e innovación en las nuevas redacciones (pp. 9-28). Editorial Universidad del Rosario.

\section{AUTORAS:}

\section{Juliana Colussi}

Actualmente es profesora asociada e investigadora del Programa de Periodismo y Opinión Pública de la Universidad del Rosario (Colombia). Doctora y Máster en Periodismo por la Universidad Complutense de Madrid (España). Sus principales líneas de investigación se centran en la formación de periodistas, innovación en los medios, periodismo móvil, periodismo de inmersión y desinformación en procesos políticos. Ha publicado más de 25 artículos en revistas internacionales indexadas. Es investigadora principal del proyecto de investigación "Observatorio de periodismo móvil en Iberoamérica" y del semillero de investigación "Estudios sobre periodismo móvil en Colombia".

juliana.colussi@urosario.edu.co

Orcid ID: https://orcid.org/0000-0002-6324-3857

Google Scholar: https://scholar.google.com/citations?user=G2Y 6x8AAAAJ\&hl=en

\section{Thays Assunção Reis}

Profesora del programa de Periodismo de la Universidad Federal de Tocantins (Brasil). Doctoranda en el Programa de Posgrado en Comunicación de la Universidad Estatal de Río de Janeiro (Brasil). Máster en Periodismo por la Universidad Estatal de Ponta Grossa. Licenciada en Periodismo por la Universidad Federal de Maranhao y en Historia por la Universidad Estatal de Maranhao.

thays.jornalista@gmail.com

Orcid ID: https://orcid.org/0000-0001-6826-1096

Google Scholar: https://scholar.google.com.br/citations?user=4xHiWsgAAAAJ\&hl=pt-BR 